\title{
UTILIZAÇÃO DE FITASE EM RAÇÕES PARA COELHOS EM CRESCIMENTO
}

\author{
Marcelo Gaspary Martins ${ }^{1}$, Luiz Carlos Machado', Adriano Geraldo1, Bruna Pontara \\ Vilas Boas Ribeiro', Luiz Otávio Rodrigues Pinto ${ }^{1}$
}

\author{
${ }^{1}$ IFMG - Campus Bambuí \\ Correspondência: Marcelo Gaspary Martins: marcelogaspary@gmail.com
}

\begin{abstract}
RESUMO: A cunicultura é uma atividade estratégica do ponto de vista econômico e da sustentabilidade ambiental. $\mathrm{Na}$ atual nutrição de precisão, a maximização do aproveitamento dos nutrientes é otimizada pelo uso de aditivos como as enzimas exógenas. Este trabalho objetivou avaliar o efeito da utilização da enzima fitase sobre o desempenho produtivo e digestibilidade em coelhos em crescimento. Foram utilizados 40 animais da raça Nova Zelândia Branca, distribuídos em cinco diferentes tratamentos, sendo uma dieta referencia e mais quatro dietas experimentais com a inclusão de 500, 1000, 1500 e 2000 FTU fitase por quilo de ração. Os animais foram distribuídos em um delineamento inteiramente casualizado com 5 tratamentos e 8 repetições. Para estudo do desempenho foram avaliados o peso aos 55 dias, peso aos 75 dias, consumo de ração, o ganho de peso diário e a conversão alimentar. Para estudo de digestibilidade, foram determinadas a digestibilidade da matéria seca, matéria mineral, matéria orgânica, proteína bruta, energia e fósforo. Não foram observadas diferenças significativas $(P<0,05)$ para a maioria dos parâmetros de desempenho avaliados, sendo observada melhora apenas na conversão alimentar considerando todo período experimental, onde houve melhora a partir da inclusão da enzima. Em relação à digestibilidade dos nutrientes, nenhum dos princípios nutritivos foi influenciado pela adição de diferentes níveis de fitase $(P>0,05)$. Outros trabalhos confirmativos devem ser desenvolvidos.
\end{abstract}

Palavras-chave: conversão alimentar; cunicultura; enzimas exógenas

\section{USE OF PHYTASE IN DIETS FOR GROWING RABBITS}

\begin{abstract}
The rabbit breeding is a strategic activity in terms of economic and environmental sustainability. In the current nutritional precision, maximizing the utilization of nutrients is optimized by using additives such as exogenous enzymes. This study evaluated the effect of the use of phytase on growth performance and digestibility in growing rabbits. A total of 40 animals of New Zealand White, assigned to five 2 treatments, with a reference diet and four experimental diets with the addition of $500,1000,1500$ and 2000 FTU phytase per kilogram of feed. The animals were distributed in a completely randomized design with five treatments and eight repetitions. To study the performance were evaluated: weight at 55 days, weight at 75 days, feed intake, daily weight gain and feed conversion. For the digestibility study, we determined the digestibility of dry matter, mineral matter, organic matter, crude protein, energy and phosphorus. There were no significant differences $(P$ $<0.05)$ for most performance parameters evaluated, improvement was observed only in the feed considering the whole experimental period, where there was an improvement from the inclusion of the enzyme. On the digestibility of nutrients, none of the nutrients was influenced by the addition of different levels of phytase $(P>0.05)$. Other confirmatory studies should be developed.
\end{abstract}

Key Words: feed conversion; rabbit breeding; exogenous enzymes 


\section{INTRODUÇÃO}

A cunicultura é considerada atividade estratégica, devido ao fato do coelho ser bastante prolifero, produtivo, possuir carne de excelente qualidade, além de poder ser desenvolvida por produtores de pequeno, médio e grande porte e gerar baixa carga poluente. Num sistema produtivo, os custos com alimentação podem chegar a cerca de $70 \%$. Devido ao aumento crescente dos custos das matérias primas tradicionais, os pesquisadores vêm buscando alternativas que proporcionem maior aproveitamento dos nutrientes e consequente redução dos custos, como a utilização de enzimas exógenas que melhoram a digestibilidade dos nutrientes e consequente o desempenho animal, maximizando assim a eficiência de utilização dos alimentos, reduzindo a ação de inibidores de crescimento, como o fitato (Silva et al., 2000).

Para coelhos poucos trabalhos avaliaram a inclusão dessa enzima. Machado et al. (2011b) utilizaram um complexo composto por carboidrases juntamente com a enzima fitase, observando melhorias na digestibilidade dos nutrientes. Já Guo Xian (2004) observaram redução linear sobre a excreção de fósforo a partir da inclusão de níveis crescentes de fitase. Os autores também observaram efeito quadrático sobre o GPD, com os melhores resultados a partir da inclusão de 800 FTU de fitase por kg de ração. Contudo não foram observadas melhorias no consumo e conversão alimentar. Ainda não está definido, para coelhos, um nível ótimo de inclusão da enzima fitase, que proporcione maximização no desempenho e digestibilidade.

Dessa forma, objetivou-se com este trabalho avaliar a suplementação de enzima fitase para coelhos, a fim de se encontrar o melhor nível de inclusão.

\section{MATERIAL E MÉTODOS}

O experimento foi conduzido no galpão de cunicultura do Instituto Federal de Ciência, Educação e Tecnologia de Minas Gerais, campus Bambuí, iniciando-se em 26 de março de 2011, com término no dia 05 de maio do mesmo ano. Durante o período experimental, as temperaturas mínima e máxima médias foram de 18,25 e $24,25^{\circ} \mathrm{C}$, respectivamente. Foram utilizados 40 animais da raça Nova Zelândia Branca, dos 35 dias de idade (desmame) até os 75 dias. Foram utilizados cinco tratamentos, sendo: 1) Dieta referência; 2) Inclusão de 500 FTU fitase/kg de ração; 3) Inclusão de 1000 FTU fitase/kg de ração; 4) Inclusão de 1500 FTU fitase/kg de ração; 5) Inclusão de 2000 FTU fitase/kg de ração. A enzima utilizada era a Genophos $\AA$, $10.000 \mathrm{FTU} / \mathrm{g}$. As dietas experimentais foram formuladas para atender às exigências propostas por De Blas e Mateos (2010), que são de: ED 2500 $\mathrm{kcal} / \mathrm{kg}$; PB 14,50-16,20\%; PD 10,2 a $11,3 \%$; Ca $0,6 \%$; Ptotal $0,4 \%$; lisina $0,75 \%$; metionina + cistina $0,54 \%$; treonina $0,64 \%$; triptofano $0,15 \%$; arginina $0,81 \%$ e FDA 16,0 a $18,5 \%$. No período experimental, a ração foi oferecida à vontade.

Os animais foram alojados em gaiolas de arame galvanizado $(60 \times 60$ $\mathrm{cm}$ ) e distribuídos em um delineamento inteiramente casualizado, utilizando-se de 8 repetições, e 5 tratamentos, num total de 40 unidades experimentais, sendo 1 coelho por unidade experimental.

Para avaliação do desempenho dos animais, foram considerados os seguintes parâmetros: peso aos 55 dias (P55), peso aos 75 dias (P75), ganho de peso diário (GPD), consumo de ração (CDR) e conversão alimentar (CA). A $\mathrm{CA}$ foi obtida pelo quociente entre 0 CDR e o GPD. Todos os animais foram pesados no momento em que foram 
alojados nas gaiolas (início) aos 35 dias de idade, sendo depois pesados aos 55 e 75 dias de idade.

Para avaliação da digestibilidade, foram utilizados os mesmos 40 animais. O período de adaptação foi de sete dias e o período de coleta foi de quatro dias, sendo realizado controle do consumo e excreção de fezes, as quais foram coletadas com a afixação de redes coletoras. As fezes foram colhidas e armazenadas a $-18^{\circ} \mathrm{C}$ para determinação o conteúdo de matéria seca (MS), matéria orgânica (MO), matéria mineral $(\mathrm{MM})$, proteína bruta $(P B)$, energia bruta (EB) e fósforo $(P) . O$ experimento seguiu as recomendações do método de referência europeu para determinação de digestibilidade proposto por Perez et al. (1995)

Os dados foram submetidos à análise de variância e as médias comparadas pelo teste Tukey, ao nível de $5 \%$ de probabilidade utilizando os recursos computacionais do programa SISVAR.

\section{RESULTADOS E DISCUSSÃO}

Foi observado que o P55 e o P75 dias não sofreram influência dos diferentes níveis de inclusão enzimática $(P>0,05)$, o mesmo acontecendo para o GPD e consumo de ração. O maior aponte de nutrientes, disponibilizado pela ação da enzima, não foi suficiente para proporcionar diferenças significativas sobre as variáveis estudadas. Foi observada melhoria significativa $(P<0,05)$ sobre a conversão alimentar, considerando todo o período experimental (35 aos 75 dias). A inclusão enzimática melhorou a eficiência alimentar dos animais. A equação de regressão polinomial encontrada foi $Y=-4 E-10 X 3+1 E-06 X 2$ - 0,0013X+3,501 (R2 =0,99), onde $X$ : É a idade, e Y: Conversão alimentar.
Tabela 1 - Peso aos 55 dias (P55), peso aos 75 dias (P75), Ganho de peso diário (GPD), Consumo de ração (CR) e conversão alimentar (CA) de coelhos alimentados com diferentes niveis de inclusão de fitase na ração.

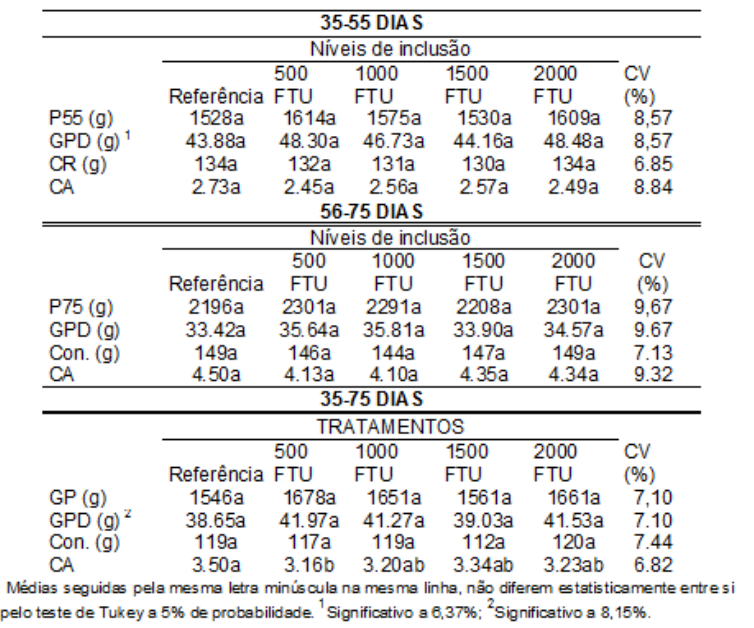

Machado et al. (2011a), utilizando a inclusão de 500 FTU/kg não observaram influência da suplementação de fitase sobre 0 desempenho dos animais que recebiam dietas simplificadas e semisimplificadas. Guo-Xian et al. (2004), observaram que o GPD foi melhorado $(p<0,05)$ com a inclusão de fitase, onde o nível de $800 \mathrm{FTU} / \mathrm{kg}$, apresentou os melhores resultados. Nota-se que os efeitos da adição de fitase para coelhos não estão bem claros.

A digestibilidade da MS, $\mathrm{MO}$ e MM não foram influenciados $(P>0,05)$ pelos diferentes níveis de inclusão da enzima fitase (Tabela 2).

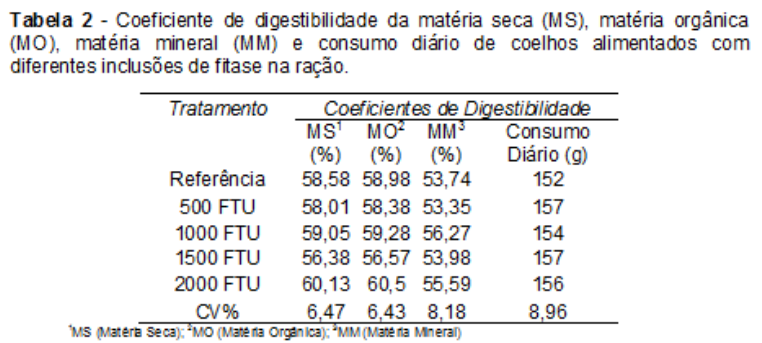

Foram encontrados, nesse experimento, valores de digestibilidade da MS e MO inferiores aos encontrados por Arruda et al.(2002), que avaliaram dietas contendo diferente níveis de amido, e encontraram valores de 65,03 e $80,68 \%$ respectivamente. 
O coeficiente de digestibilidade da MM encontrado, foi inferior ao encontrado por Ferreira et al. (2006) que encontraram coeficiente médio $58,63 \%$.

A digestibilidade dos demais nutrientes pode ser visualizada na tabela 3. Percebe-se que a digestibilidade do $P$, EB e $P B$ não foi influenciada $(P>0,05)$ pelos diferentes níveis de inclusão da enzima fitase.

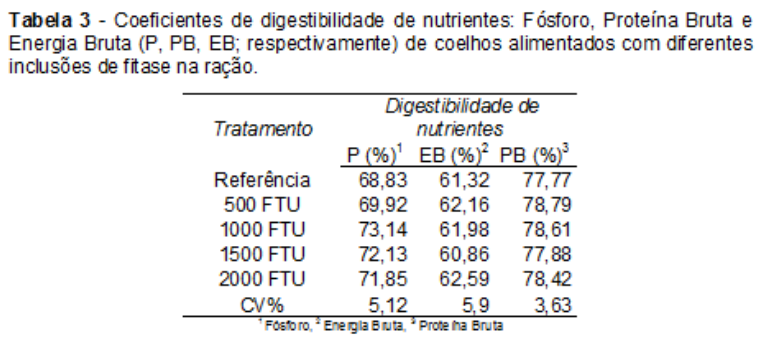

Arruda et al. (2002), utilizando-se de casca de soja como fonte fibrosa, encontrou valores para digestibilidade da proteína bruta e energia bruta na ordem de $69,10 \%$ e $61,74 \%$, para a proteína e energia respectivamente, sendo o segundo valor semelhante ao aqui observado. Nota-se que o coelho é um animal eficiente no aproveitamento de proteína.

Em relação à digestibilidade do Fósforo, Furlan et al. (1994), utilizando coelhos em crescimento alimentados com dietas a base de farelos de soja, trigo e arroz; encontrou coeficientes de digestibilidade para 0 nutriente nas dietas de 64,92\%, 55,52\% e 15,33\%, respectivamente, valores inferiores aos encontrados neste experimento.

Os resultados aqui observados discordam dos observados por Machado et al. (2011b) que percebeu melhorias quando fora adicionada enzima fitase em dietas para coelhos em crescimento. Já quando comparado a Guo Xian (2004) obteve uma redução linear do fósforo a medida em que aumentava o nível de fitase nas rações contudo sem observar melhorias no consumo e conversão alimentar.
Para maior elucidação da utilização de fitase em dietas para coelhos, são necessárias novas pesquisas com diferentes complexos enzimáticos e níveis de inclusão, além de um maior número de animais por repetições, possibilitando maior volume de dados e resultados mais claros.

\section{CONCLUSÃO}

A adição da enzima fitase, em níveis de 500, 1000, 1500 e 2000 FTU/kg, proporcionou melhorias na conversão alimentar, considerando todo o período experimental. A enzima fitase, nos níveis de 500 a 2000 FTU/kg, não proporcionou melhoria significativa na digestibilidade dos nutrientes. Outros estudos avaliando a inclusão enzimática são necessários para melhor compreensão do fornecimento de enzimas em rações para coelhos.

\section{REFERÊNCIAS}

ARRUDA, A.M.V.; LOPES, D.C.; FERREIRA, W.M. et al. Digestibilidade aparente dos nutrientes de rações contendo diferentes fontes de fibra e níveis de amido com coelhos em crescimento. Revista Brasileira de Zootecnia, v.31,n.3, p.1166-1175, 2002.

De BLAS, J.C; MATEOS, G.G. Feed formulation. In: DE BLAS, C., WISEMAN, J. The nutrition of the rabbit. 2. Ed. Cambridge: CAB International, p.222-232, 2010.

FERREIRA W. M.; HERRERA A. D. P. N.; SCAPINELLO, C. et al. Digestibilidade aparente dos nutrientes em dietas simplificadas baseadas em forragens para coelhos em crescimento e valor nutritivo das fontes fibrosas. 43 Reunião Anual da Sociedade Brasileira de Zootecnia. João Pessoa, 2006.

FURLAN, A.C.; TAFURI, M.L.; ROSTAGNO, H.S. et al. Digestibilidade do fósforo dos farelos de arroz, de soja, e de trigo, para coelhos em crescimento. Revista Brasileira de Zootecnia, v.23, n.5, p.823-828,1994.

GUO-XIAN Z.; ZHI-RUA F.; GUA-ZONG L. 2004. The effects of supplemental microbial phytase in dietas on the growth performance and mineral excretion of rabbits. In: WORLD RABBIT 
CONGRESS, 8, 2004, Puebla. Proceedings...

Puebla, 2004. p. 1114-1120.

MACHADO L. C.; FERREIRA W. M.;

SCAPINELLO, C. et al. ; Efeitos da adição de enzimas exógenas em dietas simplificadas e semi simplificadas sobre o desempenho produtivo de coelhos em crescimento. In: Reunião Anual da Sociedade Brasileira de Zootecnia, 48. Belém, 2011. Anais... Belém, 2011. CD ROM.

PEREZ J. M.; CERVERA C.; FALCÃO E CUNHA L. et al. European ring-test on in vivo determination of digestibility in rabbits: reproducibility of a reference method compared with individual laboratory procedures. World Rabbit Science, v.3, n.4, p.171-178, 1995.

SILVA, H.O; FONSECA, R.A; FILHO, R.S.G. Características Produtivas e Digestibilidade da Farinha de Folhas de Mandioca em Dietas de Frangos de Corte com e sem Adição de Enzimas. Revista Brasileira de Zootecnia, v.29, n.3, p.823-829, 2000. 